\title{
CONSERVADURISMO Y CRÍTICA LITERARIA EN LA UNIÓN DE VALPARAÍSO (1960-1966) ${ }^{1}$ \\ CONSERVATISM AND LITERARY CRITICISM IN LA UNIÓN DE VALPARAÍSO (1960-1966)
}

\author{
Eddie Morales Piña \\ Universidad de Playa Ancha de Ciencias de la Educación \\ Valparaíso, Chile \\ emorales@upla.cl \\ Marcos Aravena Cuevas \\ Universidad de Playa Ancha de Ciencias de la Educación \\ Valparaíso, Chile \\ marcos.aravena@upla.cl
}

\begin{abstract}
Resumen:
Este trabajo indaga en el sesgo ideológico que presenta la crítica literaria del diario La Unión de Valparaíso. Considerando una selección de escritos publicada entre 1960 y 1966 bajo la óptica de análisis del discurso propuesta por Teun Van Dijk, damos cuenta de las modalidades y del sistema de valores con que los críticos abordan el hecho literario, sosteniendo que éstos juegan un papel importante en la selección de las obras y su consiguiente interpretación para la comunidad de lectores. Se concluye que las distintas contribuciones concuerdan, de forma velada o manifiesta, con la línea editorial conservadora del periódico.
\end{abstract}

Palabras clave:

Crítica literaria; La Unión de Valparaíso; sesgo ideológico; conservadurismo.

\begin{abstract}
:
This work investigates the ideological bias presented by La Union de Valparaíso literary criticism. Considering a selection of writings published between 1960 and 1966 under discourse analysis perspective proposed by Teun Van Dijk (2003), we realize the methods and the system of values that critics use to approach a literary text, arguing that these play an important role in texts selection and its consequent interpretation for the community of readers. It is concluded that the different contributions concur with the newspaper conservative editorial policy in a concealed or manifest way.
\end{abstract}

\section{Keywords}

Literary criticism; La Unión de Valparaíso; ideological bias; conservatism

Recibido: 10 de marzo de 2019

Aceptado: 08 de noviembre de 2019

\footnotetext{
${ }^{1}$ Este trabajo es parte de la investigación HUM 18-1718 "Al abordaje de los críticos. La crítica literaria periodística en La Unión de Valparaíso, 1960-1973”. Proyecto financiado por la Dirección General de Investigación de la Universidad de Playa Ancha de Valparaíso, Concurso Regular 2016.
} 


\section{Presentación}

La presente investigación intentará demostrar el sesgo ideológico que presenta la crítica literaria publicada en La Unión de Valparaíso entre 1960 y 1966, la cual refleja, a nuestro parecer, el conservadurismo de su línea editorial. Mediante el análisis del discurso de sus críticos oficiales se harán explícitos los valores y las formas de abordaje con que se seleccionaron, analizaron e interpretaron distintas obras para informar sobre el mundo de las letras a la comunidad de lectores del periódico.

La crítica literaria fue un campo de desarrollo importante en el país durante la década de 1960, teniendo en cuenta que el período es considerado como uno de los momentos más fructíferos de su historia (Subercaseaux, Historia personal s. p.). El proceso de modernización de la actividad que tuvo lugar durante los años en comento, si bien centralizado en el contexto universitario, trajo consigo una proyección del quehacer hacia otros canales de divulgación, entre los cuales la vertiente de los medios masivos de comunicación tuvo especial dinamismo y productividad desde espacios diversos y, sobre todo, desde sistemas de creencias distintos (Ochoa 62-63).

En el último tiempo, el tema de la ideología en la crítica literaria en prensa escrita ha sido eje de un número variado de trabajos y de encuentros académicos ${ }^{2}$, aunque ciertamente focalizados en la producción reciente y de difusión nacional. En consecuencia, el abordaje de este aspecto requiere de un examen retrospectivo que amplíe el espectro temporal de observación con tal de analizar el proceso de superación del impresionismo como forma de aproximación literaria, incluyendo medios escritos de divulgación regional en razón de que el auge de la disciplina no sólo sustentó las secciones y los suplementos literarios de los periódicos de alcance mayor sino también a aquellos de menor extensión, normalmente ligados a una ciudad o a una provincia.

En razón de lo expuesto y a partir de la noción de que las ideologías constituyen conjuntos articulados de creencias sociales compartidas y configuradas por un grupo desde el conflicto de un "Nosotros contra Ellos" (Van Dijk 16), en este trabajo haremos referencia al origen de La Unión y a las circunstancias históricas en las que se gestó su creación en el Puerto a finales del siglo XIX, como también a la contingencia nacional e internacional durante nuestro período de estudio con miras a establecer el esquema ideológico del diario y los parámetros contextuales para el análisis de las unidades

\footnotetext{
${ }^{2}$ Véase Mayorga, Nitrihual, Herrera y Fierro 202; Espinosa, Dos aproximaciones s.p.; Espinosa, Crítica 13. Para el problema de la neutralidad ideológica de los medios y de los críticos, véase Espinosa, La crítica literaria chilena 7-8.
} 
discursivas seleccionadas. Luego de ello presentaremos nuestra investigación de la crítica del periódico para, finalmente, concluir con algunas reflexiones sobre nuestro objeto de estudio.

\section{La Unión de Valparaíso (1885-1973)}

La Unión fue un diario matutino de divulgación regional, impreso y publicado en la ciudad de Valparaíso entre 1885 y 1973, que estuvo orientado a la promoción de los principios y los valores de la Iglesia Católica. En sintonía con los lineamientos del ideario conservador en gran parte de su trayectoria, este periódico sale a la luz en el ambiente de polarización que experimentó la escena política nacional en el marco del proceso de secularización del Estado impulsado por el entonces gobernante Partido Liberal en las últimas décadas del siglo XIX.

La promulgación de las Leyes Laicas ${ }^{3}$ bajo la administración de Domingo Santa María (1881-1886) provocó un hondo descontento entre las filas del Partido Conservador, dada su afinidad con el clero y su postura de defensa de las libertades y los derechos eclesiásticos en su relación con el sector estatal. Imposibilitados de ejercer presión al gobierno por su baja representación en el Congreso, los conservadores debieron buscar otros caminos fuera del ámbito parlamentario para hacer frente a los embates de los sectores anticlericales y expresar a viva voz su descontento. De esta forma, "la tribuna, los comicios populares, la prensa, la asociación, esas máquinas de guerra con que se alcanza el imperio de la opinión en las sociedades modernas" (Serrano 338) se constituyeron como los grandes instrumentos del conservadurismo para la difusión de sus ideas y sus principios. Uno de esos dispositivos, particularmente, cobró especial relevancia en el contexto que nos convoca: la prensa religiosa.

Desde mediados del siglo XIX, las publicaciones periódicas de promoción católica experimentaron un sostenido crecimiento. Acicateadas por el conflicto IglesiaEstado, las iniciativas periodísticas dirigidas tanto por figuras del Partido como por miembros de la jerarquía eclesiástica y de asociaciones militantes fueron aumentando de forma constante entre 1856 y 1891 (Castillo 850). Diarios como El Bien Público (1863), El Independiente (1864), La Estrella de Chile (1867), El Mensajero del Pueblo (1870) y El Estandarte Católico (1874) se transformaron en el vehículo de canalización y de defensa del sentir de una comunidad frente al laicismo gubernamental. Unos cuantos

\footnotetext{
${ }^{3}$ Conjunto legislativo que fijó el traspaso al Estado de una serie de funciones que eran de competencia exclusiva de la Iglesia Católica en la época.
} 
años después, La Unión se vendría a sumar desde Valparaíso a este conjunto para llevar adelante también esta cruzada de fe y de libertad.

Fundado con el patrocinio del Consejo Departamental de la Unión Católica de Chile $^{4}$ como su primer órgano de publicidad institucional (Lyon 179), el periódico tuvo desde un comienzo un perfil bastante definido. Contando en sus primeros años con la participación del conservador Zorobabel Rodríguez (1839-1901) en la redacción principal, La Unión asumió las tareas de defender "con entera independencia los principios religiosos" y de velar por el resguardo de la "moralidad política y administrativa" (Grupo de eminentes ciudadanos 5) en el manejo del país. En consonancia con esto, el diario se declaró en su primera edición como una tribuna "infatigable en llamar a la acción a los hombres de buena voluntad" para entablar batalla al "liberalismo autoritario con sus reformas inconsultas o mal intencionadas" y para abogar por que "la libertad, toda la libertad, nada más que la libertad" (Ideas y propósitos 1) sea una realidad concreta e indiscutible. Así fijadas las coordenadas de su carta de navegación, La Unión inicia su camino en el periodismo desarrollando una línea editorial de tendencia conservadora que, con el correr de los años y ya superado el fragor de la contienda religiosa, supo resguardar y proseguir en otros momentos de álgido debate en la esfera pública, tal como fue la década de los sesenta.

Teniendo como marco la coyuntura internacional de la Guerra Fría y un ambiente interno marcado por un imaginario de transformación social (Subercaseaux, Historia de las ideas 27; Torres Dujisin 30), el periódico tomó parte activa en la discusión ideológica que por aquel entonces embebía el clima político y cultural del país, exaltando los valores nacionales y dando cuenta de las repercusiones negativas de la Revolución Cubana (1959) y de la presencia creciente de las fuerzas de izquierda en el panorama local.

Haciendo eco de lo dispuesto en la Carta Encíclica Divini Redemptoris (1937) de Pío XI, se posicionó “a la vanguardia de la inquietud patriótica" para "sostener el ideal por sobre las conveniencias materiales" y para sindicar al marxismo como "la fuerza antinacional que encierra el máximo peligro para la civilización”, argumentando que "su filosofía destructora de la libertad del hombre, la cruel inescrupulosidad de sus métodos políticos [y] la arrogancia de su poderío" constituyen serias amenazas "contra

\footnotetext{
${ }^{4}$ La Unión Católica de Chile fue una asociación militante creada en 1883 para defender los intereses católicos en el país.
} 
nuestra soberanía e integridad territorial" (Presencia de La Unión 3). Aunando de esta manera catolicismo, nacionalismo y liberalismo como matrices de su discurso (Casals 40), el diario exhibió una postura que, además de mostrar el temor que la derecha experimentó como grupo al verse desplazada de la conformación del mapa político (Correa Sutil 251), devela con claridad el rasgo de identidad que coloca en evidencia el esquema ideológico de filiación conservadora del equipo editorial: el sentimiento anticomunista.

La idea de que "nuestra democracia se encuentra en la indefensión ante la conspiración que contra ella ha tramado y está ejecutando el comunismo internacional" (Nueva advertencia 6) y la férrea convicción de que "el catolicismo no puede colaborar, ni en forma directa, ni en forma indirecta, con las huestes marxistas" (Los católicos y el comunismo 4) sirvieron así de base conceptual para intentar movilizar a los ciudadanos de Valparaíso y de Aconcagua frente a la contingencia de la época, incluso más allá de las páginas de opinión política. En efecto, el sistema de creencias antimarxistas bajo el cual el periódico interpretó la realidad de su tiempo no sólo se logra apreciar en la retórica defensiva presente en estas columnas sino también en una sección cuyo potencial fue siempre de especial interés en cuanto plataforma efectiva para incidir en el juicio de los lectores: el segmento de crítica literaria.

\section{La crítica literaria en La Unión (1960-1966)}

La Unión reconoció desde sus inicios el poder de la cultura para influir en la opinión pública. El deseo de no ser sólo "un diario exclusivamente batallador" sino también "un servidor activo de los intereses comerciales y de la cultura" para "llegar [así] al corazón mismo de los indiferentes y de los adversarios" (Grupo de eminentes ciudadanos 5) fue uno de sus principales objetivos a partir de su creación en 1885. Por ello, no resulta de extrañar que el matutino tuviera particular dedicación por el fenómeno literario, cubriendo las novedades desde su óptica de análisis y difundiendo información sobre concursos, conferencias y encuentros que tuvieran lugar en Valparaíso.

La crítica literaria publicada en La Unión entre 1960 y 1966 destaca por ser un discurso permeado por el esquema ideológico conservador y anticomunista por el que se rige la actividad periodística del diario. Resulta significativo en este contexto que los comentarios literarios se hubieran publicado junto a la columna editorial, un espacio fundamental pues constituye el lugar por excelencia desde donde "se opina, se orienta, 
se forma criterio" (Veracidad 65) ante los acontecimientos de la época. Esta cercanía en la disposición espacial de los textos viene a constatar el reconocimiento que los integrantes del equipo de redacción otorgaban al poder persuasivo del abordaje crítico de la literatura: conscientes de su capacidad como discurso intermediador entre obra y lector, asumieron firmemente que cada palabra "se halla al servicio de una visión de mundo" (Julià 22) a la hora de comentar, valorar y juzgar una creación literaria.

A pesar de que la presencia de las creencias antimarxistas en los textos críticos varía en razón de la naturaleza del soporte metodológico que sustenta las interpretaciones del crítico y de cuán manifiesto es su compromiso con los principios del sistema valórico conservador, las distintas contribuciones de escritores, académicos y profesionales de distintas áreas concuerdan en términos generales con la línea editorial del periódico. De este modo, la "posición vigilante" adoptada por el diario vino a extrapolarse a las aproximaciones literarias de una manera tal que, al momento de establecer juicios, se dictaminaba lo que debía ser leído para lograr “desperta[r] la conciencia ciudadana" (Veracidad 65) frente a las problemáticas de su tiempo.

Si bien existe presencia de una serie de colaboraciones periódicas y esporádicas, entre las cuales se hace necesario mencionar las del escritor Salvador Reyes (18991970), del periodista Guillermo Arrieta Muñoz (1917-2008) y de los sacerdotes Fidel Araneda Bravo (1906-1992) y Alberto Arraño Acevedo (1914-1998), a la hora de ingresar al estudio del sesgo ideológico conservador que presenta la crítica nos centraremos en el trabajo de los dos críticos oficiales durante nuestro período de estudio: el académico Cedomil Goic (1928), y el abogado y periodista Tomás P. Mac Hale (1944-2003).

\subsection{Cedomil Goic (1928)}

La presencia de Cedomil Goic en los primeros años de nuestro período de estudio muestra el contacto estrecho que La Unión mantuvo con el mundo académico de la ciudad-puerto. Proveniente del ámbito universitario, el académico aunó en sí la doble labor de ser crítico oficial del periódico al mismo tiempo que se desempeñaba como docente en la Sede Valparaíso del Instituto Pedagógico de la Universidad de Chile. La lectura del segmento "Revista de Libros", publicado semanalmente en la edición dominical entre 1958 y 1961, revela precisamente una forma de aproximación literaria 
acorde con los vientos de cambio que se comenzaban a sentir por aquellos años en la actividad crítica académica.

Gran parte de las contribuciones recopiladas exhibe un ejercicio crítico que se sustenta en una concepción de la literatura como estructura de lenguaje, esto es, como un constructo de elementos que se interrelacionan mediante vínculos de sentido inmanente, y autónomo frente a su circunstancia (Situación 337). La formación del académico en diversas corrientes críticas europeas y norteamericanas le permite reconocer, ahora bien, las limitaciones de este concepto estructural y tomar distancia de su inherente ahistoricidad, asumiendo una perspectiva que considera aquellos vínculos intrínsecos en sincronía y en diacronía con el sistema literario (Cuadros s. p.). En consecuencia, llegado el momento de comentar una novela, una antología de cuentos, un poemario o una pieza dramática, Goic considera que aspectos tales como el tratamiento formal, la originalidad creadora y la interpretación histórica del entramado interno resultan relevantes para determinar su autenticidad y su valor literarios.

La lectura de la crítica que el académico realizó bajo este instrumental metodológico evidencia un marcado privilegio por los trabajos creativos de escritores chilenos coetáneos. Creemos que este criterio de selección textual se debe preferentemente a la coyuntura de pugna generacional que se dio en el panorama literario del país a partir de los primeros años de la década de los sesenta y, dentro de este contexto, a la convergencia de los fundamentos de su abordaje crítico con el sistema de preferencias que a esa fecha manifiesta la sensibilidad emergente. Sin embargo, nos llama la atención en este ámbito la nota negativa con que Goic califica de manera recurrente la producción asociada a la corriente vigente en ese entonces, al grado de que varias de sus contribuciones constituyen voces de alerta frente a ciertos "ideales de tipo extra-estético" que promueven un "plebeyismo en estado virulento y proliferante" e impiden "la revelación de nuevas preferencias, frescas y prometedoras" (El panorama 135) en el campo literario nacional. Pensamos que en esta insistente llamada de atención no sólo aflora el desasosiego del crítico frente a un eventual estatismo de las formas literarias, sino también la preocupación editorial acerca de la influencia perniciosa que estos principios extrínsecos -sobre todo de aquellos idearios de raigambre política y social- tienen sobre los escritores noveles, dejando entrever así los hilos ideológicos que se entretejen con el andamiaje estructuralista que sustenta esta postura. 
En el plano de la creación lírica, la presencia de esta inquietud aparece con mayor relieve en el comentario que Goic dedica el 14 de febrero de 1960 a los poemarios Cantos de pan (1959) de Sergio Hernández, Sed por dentro (1959) de Nicolás Ferraro, y Descendimiento (1959) de Rosa Cruchaga. La reflexión que realiza sobre la obra del primer poeta - del mismo modo extensiva para el trabajo creativo del segundo- es bastante elocuente para apreciar la opinión negativa que el crítico posee ante los lineamientos poéticos en boga y el influjo que éstos tienen en la práctica escritural de la nueva cohorte de escritores:

Poesía de lo elemental - cantos de pan- y cotidiano es ésta actualizada con una poética igualmente elemental. ¿Cuáles son las posibilidades de una poética semejante? Por cierto muy limitadas, por cierto muy practicadas, por cierto con una vigencia muy extendida. ...

Hemos señalado los riesgos actuales que encierra la avasalladora vigencia de ciertas preferencias gregarias que están arrasando con las posibilidades más inmediatas de nuestra lírica joven. Es el momento de decir con Antonio Machado: "Acaben los ecos, empiecen las voces". (11)

Las resonancias reverberantes de la generación en vigencia son, en palabras de Goic, las principales responsables de la inclinación de Hernández y Ferraro hacia el despliegue "censurable" de "alusiones al plano histórico social, [...] político y económico" y hacia el desarrollo de una "poesía verbosa" que atenta contra la necesaria búsqueda de "una forma íntima y personal que traduzca fielmente su auténtico ser poético" (11). Este reproche a la propensión de ambos autores cobra un realce superior llegado el momento de comentar la poesía de Cruchaga, cuya voz "clara y poderosamente distinta" trae una "palabra nueva, inusitada" (22) que ilumina el panorama poético local:

Se trata de una colección de poemas verdadera y auténticamente excepcional en la literatura poética de los últimos años en nuestro país. Y aunque sus fuentes, sus orígenes, pueden ser remontados con facilidad, su originalidad, la peculiaridad personalísima que la aparta de sus orígenes afincándose en ellos, no puede ser discutida [...] Su obra, apenas reciente, la coloca de improviso en un lugar privilegiado.

Tenemos ahora entre manos un libro poco común. (22)

El acusado contraste que el crítico establece entre los poemarios de Hernández, Ferraro y Cruchaga señala en forma clara al lector de La Unión los efectos adversos que 
tienen las preferencias vigentes sobre la conciencia creativa de los nuevos poetas, sosteniendo, a propósito de Descendimiento, que la genuina poesía constituye "un activo gesto creador" (22) que nunca responde, tal como sucede con Cantos de pan y con Sed por dentro, a una "presión gregaria de cierto gusto” (11). Dice Goic: “¿No es acaso el momento de abandonar los términos manidos de la poética en boga siendo como es ésta una poética escuálida y por momentos miserable?" (11).

La columna que dedicó, ahora en el plano de la narrativa, a la novela de Juan Godoy Sangre de Murciélago (1959) el 31 de julio de 1960 proyecta con aún mejor precisión esta línea de pensamiento. A pesar de que destaca la figura del autor oriundo de Chillán en su comentario, resulta llamativo que una parte importante de éste sea una reprobación del quehacer de sus compañeros de generación. Según sostiene el crítico, las preferencias con que estos autores configuran el mundo novelesco responden más que nada a "ciertas formas mostrencas que encuentran su razón de ser en la común alusión -realista social- a la realidad exterior, al suceder histórico" (16). Esta disconformidad no sólo se debe, pensamos, al tenor involutivo que atribuye al desarrollo que experimentó la novela en razón de su inclinación por el tratamiento espacial de la vida proletaria, sino también a la inspiración marxista que subyace en esta práctica escritural. En este sentido, critica la insuficiente capacidad autorial para asumir los nuevos recursos y procedimientos literarios, y el afán por fijar su horizonte en criterios político-sociales más que en la necesaria renovación de la actividad escritural:

[...] el novelista de esta generación ofrece como peculiarísima nota la precariedad de los resultados frente a la tarea impuesta. Puesto el acento en la intención de mostrar con fidelidad la realidad social sometida a la estrecha legalidad de sus determinismos internos, fáciles y claros en la teoría elemental que los sustenta; afanados en hacer obra de trascendencia y sentido popular; no dejaron de mano la ambición de permanecer a la altura de las novedades de la técnica novelística actual -de los más variados modos y maneras-, con lo cual inhibieron -es fácil de concluir- las posibilidades de un fácil acceso del lector al mundo novelesco. (16)

Creemos que el marcado énfasis que Goic confiere a la adhesión de los escritores a los lineamientos del realismo socialista va más allá de señalar la eclosión de una literatura comprometida poco innovadora (Historia 220), ya que junto con esto observamos el establecimiento de un juicio sustentado en uno de los principios de mayor relevancia para el equipo editorial de La Unión: la idea de libertad. Al enaltecer 
en el comentario sobre Sangre de Murciélago la figura de Godoy entre aquellos escritores "que consiguen levantarse sobre la misma estructura general de la sensibilidad de su generación con la suficiente libertad creadora" (16) el crítico construye una imagen que busca persuadir al lector de nuestro diario de que una escritura creativa bajo el signo marxista es incapaz de contribuir al progreso histórico de las formas literarias por encontrarse coaccionada por la consigna política.

\subsection{Tomás P. Mac Hale (1944-2003)}

Siguiendo este mismo derrotero, aunque desde un ejercicio crítico de corte impresionista, las contribuciones de Tomás P. Mac Hale dan cuenta de las mismas preocupaciones que Goic deja entrever tras el velo de la teoría ante la irrupción de las ideas marxistas en las letras del momento. Desde sus segmentos "Libros" y "Correo Literario", publicados semanalmente entre 1961 y 1965, el crítico muestra con singular vehemencia su postura discrepante en torno al desarrollo de la literatura durante nuestro período de estudio.

Mac Hale coloca en evidencia en su crítica un franco rechazo a la literatura de compromiso político. La lectura de sus contribuciones proyecta una actitud negativa hacia los autores que priorizan en su producción la transmisión de valores políticosociales por sobre el desarrollo estético-literario, tornándose particularmente severa cuando trata sobre trabajos que defienden ideas y principios de filiación comunista. En este sentido, el espacio literario de La Unión viene a transformarse con él en una tribuna desde la que persigue contrarrestar "la estridencia propagandística" de aquellos libros que "pretende[n] condenar respetables posiciones [y] exaltar el extremismo más odioso" (Literatura 10) mediante la consagración de obras nacionales y extranjeras que coinciden con sus gustos e inclinaciones personales para entender y apreciar la literatura.

Definido como un hombre dogmático y de ferviente fe religiosa (Ibáñez Langlois 29), Mac Hale se sitúa frente a la escritura de su tiempo bajo una noción de la literatura como representación mimética de la realidad y desde una postura dialogante con la cosmovisión de la élite tradicional, desarrollando un abordaje crítico que elogia la convergencia y condena la divergencia a partir de estas características discursivas. Estos aspectos son particularmente visibles cuando dirige su atención al tratamiento 
literario de la vida aristocrática y de los valores que conforman el esquema de pensamiento conservador de este sector en las novedades literarias de la época.

El juicio positivo que realiza en 1961 sobre la novela Campo Viejo (1960) destaca la perspectiva realista que Carlos Rozas Larraín adopta para representar el espacio campestre como elemento conformante de la identidad nacional, haciendo especial hincapié en el rescate de las costumbres señoriales y en la puesta en valor de la "verdadera faz" del campesino que esta obra ofrece en comparación con las publicaciones de otros autores que abordan el mundo rural desde un eje semántico de "espíritu disímil”":

El encanto de Campo Viejo radica, a mi entender, en dos virtudes fundamentales. La primera, es haber podido describir sus escenarios con la pericia de quien los conoce a fondo, evocándolo en toda su majestad y belleza. Y la segunda es dar a conocer la verdadera faz del campesino chileno de otrora, de la cual mucho deben aprender los que hoy laboran los mismos terrenos, tal vez con similar eficacia, pero en todo caso con espíritu disímil. Su autor, Carlos Rozas Larraín, ha seguido la huella de Federico Gana, el gran señor de la naturaleza campestre nacional, y ha realizado una obra auténtica con ejemplar señorío. (6)

Desde su perspectiva, Mac Hale considera que la reproducción fiel de los sectores altos de la sociedad es un tema al que se debe dedicar un especial interés. Creemos que este parecer obedece más que nada a un afán por reincorporar a los sectores aristocráticos a un lugar protagónico en la literatura chilena en un contexto poco proclive a la apropiación literaria de este grupo social considerando las tendencias políticas, filosóficas y literarias que predominan en el panorama cultural del momento. En efecto, al catalogar la obra de Adelina Casanova Vicuña La hija del pintor (1961) como "un saludable oasis dentro del fárrago novelístico contemporáneo" no puede evitar deslizar su opinión desfavorable sobre el estado general de las letras nacionales, lamentando que "la inmensa mayoría [de los escritores] ha derivado a una temática en la cual las inquietudes espirituales y metafísicas ocupan parte importante" (6).

A la luz de lo anterior, no resulta de extrañar la calificación deficiente con que evalúa Punta de rieles (1960) de Manuel Rojas en una columna publicada con motivo de su tercera edición en julio de 1963. Los reparos que atribuye a la figura de Fernando Larraín Sanfuentes, el personaje "de lo que supone constituye la aristocracia y uno de sus genuinos representantes" (Correo 6), tienen su origen en el exiguo conocimiento que el escritor posee de esa realidad social: 
"Punta de rieles" es un signo evidente de la crisis, por no decir de la decadencia de Manuel Rojas y es una novela falsa, hueca, carente de sentido y trascendencia. El paralelo que pretendió efectuar se quiebra muy pronto, demuestra unilateralidad en sus apreciaciones, porque si el autor a través de sus andanzas conoció a fondo el mundo de Romilio Llanca, el de su antípoda ni siquiera puede jactarse de haberle dado una leve y fugaz mirada, pues si no pertenece a un mundo determinado, ¿cómo se va a narrarlo hasta en sus mínimos detalles? (Correo 6)

Una estimación totalmente distinta a la del texto de Rojas se advierte en la columna que dedica en 1961 a El príncipe y las ovejas (1961) de Enrique Lafourcade. A diferencia del juicio sobre Punta de rieles, Mac Hale elogia la capacidad del escritor a la hora de representar espacios y personajes característicos de la élite social, al mismo tiempo que advierte con entusiasmo la inclusión de un conjunto de valores religiosos que son distintos a los que las tendencias en boga difunden durante la época:

Contrastando con una considerable sección de las actuales corrientes literarias, Lafourcade presenta un cuadro esencialmente narrativo y descriptivo, eludiendo toda disgresión [sic] metafísica por considerarla incompatible con el espíritu de la sociedad que pinta. Mas no por ello la obra carece de contraposición entre las dos corrientes filosóficas de la vida humana, pues en "El príncipe y las ovejas" hay oposición entre valores morales, como factores determinantes del futuro eterno, y que la balanza del bien y del mal, empleada en esta vida, va a determinar, cual índice de conducta, el destino de la existencia posterior a la terrena, o sea, la eterna. Lafourcade, aunque no toca esos terrenos indirectamente llega a ellos. (10)

La apreciación positiva que Mac Hale realiza del trasfondo espiritual en esta novela de Lafourcade constituye una variable constante y distintiva de su crítica. Conciente de su labor como parte integrante del equipo editorial de La Unión (Veracidad 65) y de su ferviente devoción religiosa, la pintura seria de los valores cristianos en la creación literaria del período se vuelve para él un asunto de importancia fundamental. De esta manera, la valoración literaria se transforma, como podemos observar en el comentario que realiza hacia 1962 sobre Versos de ciego (1961) de Luis Alberto Heiremans, en un mecanismo discursivo que permite dar un "golpe frontal al materialismo de la hora presente" y mostrar, de acuerdo a su perspectiva, a lo que debe propender una obra literaria en tiempos difíciles: proyectar "sobre el hombre contemporáneo una voz que alienta y dignifica" (6). 


\section{Conclusiones}

A pesar de que el equipo editorial de La Unión estaba consciente de que las “esencias nacionales, aquellas que en 1885 se hallaban en todo el poderío de su pujanza" ya "no poseen la misma fuerza, ni el mismo arrastre inmediato" (Presencia de la Unión 3), el segmento de crítica literaria del diario se mantuvo como un espacio fundamental a la hora de establecer una postura frente al panorama político y cultural de los años sesenta. De este modo, la sección constituyó un engranaje relevante de su dispositivo ideológico para proyectar y difundir las directrices conservadoras en la audiencia de lectores de Valparaíso y de Aconcagua.

Al observar los comentarios publicados en La Unión durante nuestro período de estudio, hemos advertido que la crítica de Cedomil Goic y la de Tomás P. Mac Hale concuerdan con la línea editorial anticomunista del periódico. La figura de ambos profesionales viene a coincidir, en este sentido, con la idea de Àlex Broch sobre el crítico-topógrafo que busca trazar un mapa de campo para orientar el recorrido por los caminos de la literatura (Cit. en Ballester 76): tanto el juicio negativo de Goic acerca del tradicionalismo formal y de los valores extra-estéticos de la vigencia generacional neorrealista como el rechazo de Mac Hale hacia la literatura de compromiso político izquierdista pueden considerarse como señales de advertencia y de encauzamiento que buscan guiar al lector en una dirección distinta y opuesta al signo marxista. Ahora bien, hemos constatado que en este trabajo de cartografía literaria existen matices significativos en razón de los diferentes enfoques con que los críticos abordaron la producción del momento.

La naturaleza del soporte teórico-metodológico juega un papel importante en la expresión de la subjetividad del crítico llegado el momento de valorar una obra. Por un lado, la adscripción de Goic al método estructuralista le provee a su crítica un aparataje conceptual que le permite realizar juicios desde una idea inmanente de la creación literaria, pero contribuye en cierta medida a disimular su postura personal dado que tiende en mayor medida a lo analítico antes que a lo evaluativo (Eagleton 62); por su parte, el acercamiento impresionista de Mac Hale transparenta de inmediato su sistema valórico conservador al estimar la pertinencia de las ideas y los contenidos tratados en los escritos literarios en razón de su gusto individual. Concluimos entonces que Goic converge en forma velada con el esquema editorial mientras que Mac Hale lo hace de manera manifiesta. 
Más allá de las diferencias entre las formas de aproximación que poseen las personalidades que comparten la tribuna literaria de La Unión, la revisión de la crítica nos permitió demostrar que el discurso crítico sobre la literatura no sólo tuvo nicho en los medios de comunicación de mayor repercusión, sino también en el espacio periodístico de difusión regional. Del mismo modo, nos permitió apreciar al diario como un espacio ideológico interesante de analizar en el contexto de renovación que se suscitó en la década de los sesenta, toda vez que en él se desarrollaron voces desde la provincia que también tenían algo que decir en una época de reconocida importancia para la evolución del discurso crítico literario y para el desarrollo de la cultura en el país.

\section{Bibliografías}

Ballester, Josep. La formación lectora y literaria. Barcelona: Graó, 2015.

Casals, Marcelo. "La 'larga duración' del autoritarismo chileno. Prácticas y discursos anticomunistas camino al Golpe de Estado de 1973". Revista de Historia y Geografía 29 (2013): 31-54.

Castillo, Claudia. 'La fe en hojas 'de a centavo'. Prensa católica en Chile, sus lectores y el caso de El mensajero del pueblo, 1870-1876”. Teología y vida 49.4 (2008): 837-874.

Correa Sutil, Sofía. Con las riendas del poder. La derecha chilena en el siglo XX. Santiago, Chile: Editorial Sudamericana, 2005.

Cuadros, Ricardo. "La periodización generacional de Cedomil Goic". Crítica.cl (2005): 1-14. https://critica.cl/literatura/la-periodizacion-generacional-de-cedomil-goic

Eagleton, Terry. Una introducción a la teoría literaria. México: Fondo de Cultura Económica, 1998.

Espinosa Hernández, Patricia. "Dos aproximaciones a la crítica literaria". Ojo en Tinta (2013). http://www.ojoentinta.com/dos-aproximaciones-a-la-critica-literaria

Espinosa Hernández, Patricia. "Crítica literaria en el Chile neoliberal: la invisibilización de la disidencia". Catedral Tomada: Revista de Crítica Literaria Latinoamericana 4.6 (2016): 1-14.

Espinosa Hernández, Patricia. Ed. La crítica literaria chilena. Actas del Primer Coloquio de Crítica Literaria en Prensa. Santiago, Chile: Instituto de Estética de la Pontificia Universidad Católica de Chile, 2009.

Goic, Cedomil. "El panorama literario de 1959". La Unión (Valparaíso, Chile), 23 Ene. 1960: 135.

Goic, Cedomil. "Revista de Libros". La Unión (Valparaíso, Chile), 14 Feb. 1960: 11, 22.

Goic, Cedomil. "Revista de Libros". La Unión (Valparaíso, Chile), 31 Jul. 1960: 11, 16.

Goic, Cedomil. Historia de la Novela Hispanoamericana. Valparaíso, Chile: Ediciones Universitarias de Valparaíso, 1972.

Goic, Cedomil. "La novela chilena actual: tendencias y generaciones". Obra Selecta de Cedomil Goic. Tomo II. Poesía, Teatro, Teoría e Historiografía Literarias. Sel. 
Pról. Eddie Morales Piña. Valparaíso, Chile: Ediciones de la Editorial de la Universidad de Playa Ancha, 2016. 317-330.

Goic, Cedomil. "Situación del estudio de la obra literaria como estructura del lenguaje". Obra Selecta de Cedomil Goic. Poesía, Teatro, Teoría e Historiografía Literarias. Tomo II. Sel. Pról. Eddie Morales Piña. Valparaíso, Chile: Ediciones de la Editorial de la Universidad de Playa Ancha, 2016. 331339.

“Grupo de eminentes ciudadanos creó La Unión hace 73 años”. La Unión (Valparaíso, Chile), 23. Ene. 1958: 5.

Ibáñez Langlois, Diego. “Tomás P. Mac Hale, alias Destroyer". Biblioteca Nacional Digital de Chile. Qué Pasa 297 (1976): 28-31.

“Ideas y propósitos". La Unión (Valparaíso, Chile), 23 Ene. 1885: 1.

Julià, Jordi. La mirada de Paris. Ensayos de crítica y poesía. México: Siglo XXI Editores, 2004.

“Los católicos y el comunismo". La Unión (Valparaíso, Chile), 14.Abr. 1959: 4.

Lyon, Carlos. "Memoria del Consejo Departamental de la Unión Católica en Valparaíso". Segunda Asamblea General de la Unión Católica de Chile: celebrada en Santiago. Santiago, Chile: Imprenta Victoria, Biblioteca Digital Hispánica. 1 nov 1885 al 5 nov.1985, 177-180.

Mac Hale, Tomás P. “Campo Viejo”. La Unión (Valparaíso, Chile), 03 Sept. 1961: 6.

Mac Hale, Tomás P. "La hija del pintor”. La Unión (Valparaíso, Chile), 15 Oct. 1961: 6.

Mac Hale, Tomás P. "El príncipe y las ovejas”. La Unión (Valparaíso, Chile), 17 Dic. 1961: 10.

Mac Hale, Tomás P. "Versos de Ciego (de Luis A. Heiremans)". La Unión (Valparaíso, Chile) 09 Nov. 1962: 6.

Mac Hale, Tomás P. “Correo Literario”. La Unión (Valparaíso, Chile), 09 Jul. 1963: 6.

Mac Hale, Tomás P. "Literatura para veraneantes”. La Unión (Valparaíso, Chile), 9,19 Ene 1965: 10.

Mayorga, Alberto, Luis Nitrihual, Macarena Herrera y Juan Manuel Fierro. "La construcción socioimaginaria de la mujer en la crítica literaria periodística: resultados del estudio de la producción cultural de la Revista de Libros del diario El Mercurio de Santiago de Chile". CIC Cuadernos de Información y Comunicación 18 (2013): 189-204.

"Nueva advertencia contra acción comunista". La Unión (Valparaíso, Chile), 27 Oct. 1962: 6.

Ochoa, Alejandra. "La crítica literaria periodística en Chile: 4 medios representativos en los años 60". Mapocho 45 (1998): 61-86.

“Presencia de 'La Unión' en la vida nacional”. La Unión (Valparaíso, Chile) 23. Ene. 1959: 3.

Serrano, Sol. ¿Qué hacer con Dios en la República? Política y secularización en Chile (1845-1885). Santiago, Chile: Fondo de Cultura Económica, 2008.

Subercaseaux, Bernardo. "Historia 'personal' de la crítica literaria en Chile". Dossier 4 (2007).

Subercaseaux, Bernardo. Historia de las ideas y de la cultura en Chile: desde la Independencia hasta el Bicentenario. Santiago, Chile: Universitaria, 2011.

Torres Dujisin, Isabel. La crisis del sistema democrático: las elecciones presidenciales y los proyectos políticos excluyentes. Chile 1958-1970. Santiago, Chile: Universitaria, 2014.

Van Dijk, Teun. Ideología y discurso. Barcelona: Ariel, 2003. 
Artículo. Eddie Morales Piña, Marcos Aravena Cuevas. "Conservadurismo y crítica literaria en La Unión de Valparaíso (19601966)".

"Veracidad y valentía de pensamiento". La Unión (Valparaíso, Chile) 23. Ene. 1965: 65. 